\title{
Natural Convection Characteristics of Copper-Water Nano Fluid with Two Heat Sources at the Bottom Surface in a Square Enclosure-A Numerical Study
}

\author{
Vinay Kumar Domakonda*, Farooq Shaik \\ Vignan's Foundation for Science Technology and Research, Vadlamudi 522213, Andhra Pradesh, India
}

Corresponding Author Email: drdvk_mech@vignan.ac.in

https://doi.org/10.18280/ijht.380214

Received: 6 June 2019

Accepted: 21 May 2020

\section{Keywords:}

Nusselt number, nanofluid, Rayleigh number, nanoparticles volume fraction

\begin{abstract}
Natural convective fluid flow and heat transfer in a square cavity filled with Copper $(\mathrm{Cu})$ nano particles, mixed in a base fluid (water) has been numerically studied using finite volume method. The Semi Implicit Method for Pressure Linked Equations (SIMPLE) algorithm has been used to solve the transport equations (momentum and energy). Two constant temperature heat sources of same magnitude are placed on bottom surface and the two vertical surface temperatures are kept cold, while the top surface is maintained adiabatic. The influence of Rayleigh number (RaN) (varied from 1000 to $10^{6}$ ) and nanoparticle volume fraction $(\Phi=0 \%, 5 \%, 10 \%, 15 \%$ and $20 \%)$ on fluid and heat flow characteristics has been numerically investigated and presented in the form of streamlines, velocity vectors, constant temperature lines, vertical velocity component at mid horizontal line, local and average Nusselt number. The obtained results indicate, for higher values of $\mathrm{RaN}\left(\mathrm{RaN}=10^{5}\right.$ and $\left.10^{6}\right)$ and volume fractions of nanoparticles, there is a significant increase in vertical velocity component, local and average Nusselt numbers due to increase in buoyancy forces and thermal conductivity of nanofluid.
\end{abstract}

\section{INTRODUCTION}

Natural convection heat transfer inside closed cavities has wide engineering applications such as in solar energy storage devices, cooling of nuclear reactors, electronic and mechanical components, buildings, heat exchangers, storage tanks, etc. In all of these applications, thermo physical properties of fluids enclosed inside cavities play significant role to achieve their rated efficiency. Choi et al. [1] reported that a new class of fluid is formed when nanometer sized particles of metals/metal oxides of about 10 nanometers are added to conventional heat transfer fluids (water, ethylene glycol), named as nanofluid, which has better heat carrying ability compared to its base fluids. Xuan et al. [2] experimentally determined the properties of nanofluids and reported that thermal conductivity increases with increase in volume fraction of nanoparticles, also with variation in their shape and dimension. Mathematical correlations were also developed in this study to determine convective heat transfer coefficient between nanofluids and inner tube walls. Tzou [3] investigated the instability in nanofluids and reported that the critical $\mathrm{RaN}$ decreases by two orders of magnitude for nanofluids due to combined effect of Brownian and thermophoresis of nanoparticles. Khanafer et al. [4] investigated the heat transfer in a square cavity utilizing nanofluids using different models and reported that there is a significant increase in heat transfer due to suspended nanoparticles at any Grashoff number. Putra et al. [5] conducted experiments to investigate the thermal conductivity of nanofluids $\left(\mathrm{Al}_{2} \mathrm{O}_{3}\right.$ and $\left.\mathrm{CuO}\right)$ and reported that it increases with temperature at different particle densities, concentration and at different aspect ratios of the cylinder. It was also reported that there was a significant deterioration in natural convective heat transfer coefficient inside the horizontal cylinder. Sheikhzadeh et al. [6] numerically investigated the heat transfer in rectangular enclosure filled with the $\mathrm{TiO}_{2-}$ water nanofluid and presented that the average Nusselt number $\left(\mathrm{Nu}_{\mathrm{avg}}\right)$ of the heated wall decreases with increase in aspect ratio of cavity for a given value of RaN. Aminossadati et al. [7] numerically investigated natural convection in a partially heated cavity from below and when filled with different types of nanofluids $\left(\mathrm{Cu}, \mathrm{Ag}, \mathrm{Al}_{2} \mathrm{O}_{3}, \mathrm{TiO}_{2}\right)$. It was reported that the cooling performance of the nano fluids improved due to addition of nanoparticles to the base fluid which is water, especially at low RaN. Ibtissam et al. [8] numerically developed a homogeneous heat transfer model to predict the heat transfer coefficients of nanofluids in a differentially heated square cavity for uniform and sinusoidal temperatures on its left wall. Xiong et al. [9] studied the fluid flow and heat transfer in a square cavity containing a thermal column filled with the $\mathrm{SiO}_{2}$-water nanofluid and reported that the increase in Nusselt number is more at high RaN than at low RaN. Roy [10] developed a model to determine the natural convection heat transfer coefficient of nanofluids in a square enclosure with circular, elliptical, and rectangular inner shapes. Effects of various parameterls like viscosity, thermal conductivity, Rayleigh and Nusselt numbers have been investigated by different researchers experimentally and numerically [11-14]. Bhattad et al. [15] studied the influence of various nano and hybrid nanofluids $\left(\mathrm{Al}_{2} \mathrm{O}_{3}\right.$-Multiwall carbon nano tubes and water) on heat transfer and pressure drop in a counter flow plate heat exchanger, both experimentally and numerically at different nanoparticle volume concentrations. Results of various models such as Discrete phase model (DPM) and Single-phase model were compared with the experiments in this study. It was reported that the DPM provided better results compared to the homogeneous model and the hybrid nanofluid 
has better performance. This improved performance was attributed to the higher thermal conductivity of MWCNTs compared to that of $\mathrm{Al}_{2} \mathrm{O}_{3}$. Bhattad et al. [16] conducted an extensive review on the application of various nanoparticles in refrigeration, heat pump and in air conditioning systems in different roles such as a refrigerant, lubricant and secondary fluid. Variation in different thermophysical properties of nanofluids in different roles was listed in the review such as increase in thermal conductivity, viscosity, specific heat and density with increase in nanoparticle volume concentration. Despite of vast applications of multiple heat sources on same side of the wall, as in case of natural convective cooling of electronic devices, literature on such studies is limited. In the present work, the influence of $\mathrm{RaN}$ and volume fraction of nanofluids on fluid flow and heat transfer inside the cavity filled with $\mathrm{Cu}$-Water nanofluid with two heat sources is numerically simulated using finite volume method for laminar natural convection.

\subsection{Problem definition}

Figure 1 shows the schematic representation of square cavity filled with $\mathrm{Cu}$-Water nanofluid. Two constant temperature heat sources, $\mathrm{T}_{\mathrm{h}}$ are located on the lower horizontal surface, while vertical surfaces are maintained at low temperature $T_{c}$, and the upper surface is insulated. The nanofluid flow and heat transfer inside the cavity is assumed to be steady, two dimensional, incompressible, Newtonian and laminar. Boussinesq approximation is considered to account for density variation of nanofluids and the other properties are assumed to be constant.

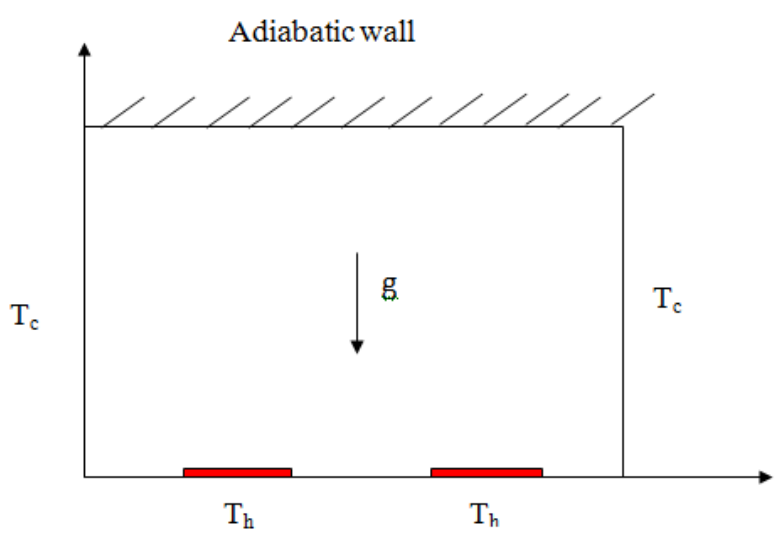

Figure 1. Schematic representation of the problem with two heat sources

Two approaches, mainly, single and two-phase models were used in the literature to study the influence of nanoparticles suspended in a fluid on the heat transfer [4, 7]. The singlephase models are simpler and efficient computationally in which the base fluid and the suspended nanoparticles are in thermal equilibrium and flow with same velocity. The twophase models are used mostly to understand the role of fluid and nanoparticles on the heat transfer and are computationally intense. Heat transfer in nanofluids is affected by several factors, such as Brownian motion, agglomeration of nanoparticles, friction between fluid and the nanoparticles, layering at solid-liquid interface, etc. Two phase models are not applicable to analyze the nanofluids in the absence of experimental data and suitable numerical studies [4]. Owing to the scarcity of literature on such experiments and complexity of two-phase models, and also because of the simplicity and accuracy, modified single phase model was considered in the present work as the main interest in this work is focused on the heat transfer process.

\section{MATHEMATICAL FORMULATION}

\subsection{Governing equations of the problem}

The fluid flow and energy equations for the steady, two dimensional, laminar natural convection in the cavity can be written in dimensional form as follows:

Continuity equation:

$$
\frac{\partial u}{\partial x}+\frac{\partial v}{\partial y}=0
$$

$\mathrm{x}$-momentum equation:

$$
u \frac{\partial(u)}{\partial x}+v \frac{\partial(u)}{\partial y}=\frac{1}{\rho_{n f}}\left[-\frac{\partial p}{\partial x}+\mu_{n f}\left(\frac{\partial^{2} u}{\partial x^{2}}+\frac{\partial^{2} u}{\partial y^{2}}\right)\right]
$$

y-momentum equation:

$u \frac{\partial(v)}{\partial x}+v \frac{\partial(v)}{\partial y}=\frac{1}{\rho_{n f}}-\left[-\frac{\partial p}{\partial y}+\mu_{n f}\left(\frac{\partial^{2} v}{\partial x^{2}}+\frac{\partial^{2} v}{\partial y^{2}}\right)+(\rho \beta)_{n f} g\left(T-T_{c}\right)\right]$

Energy equation:

$$
u \frac{\partial T}{\partial x}+v \frac{\partial T}{\partial y}=\alpha_{n f}\left[\left(\frac{\partial^{2} T}{\partial x^{2}}+\frac{\partial^{2} T}{\partial y^{2}}\right)\right]
$$

The density, diffusivity, heat capacitance, coefficient of thermal expansion,viscosity [13] and thermal conductivity of nanofliuds [14] and is determined by:

$$
\begin{gathered}
\rho_{n f}=(1-\phi) \rho_{f}+\phi \rho_{s} \\
\alpha_{n f}=k_{n f} /\left(\rho C_{p}\right)_{n f} \\
\left(\rho C_{p}\right)_{n f}=(1-\phi)\left(\rho C_{p}\right)_{f}+\phi\left(\rho C_{p}\right)_{s} \\
(\rho \beta)_{n f}=(1-\phi)(\rho \beta)_{f}+\phi(\rho \beta)_{s} \\
\mu_{n f}=\frac{\mu_{f}}{(1-\phi)^{2.5}} \\
k_{n f}=k_{f}\left[\frac{\left(k_{s}+2 k_{f}\right)-2 \phi\left(k_{f}-k_{s}\right)}{\left(k_{s}+2 k_{f}\right)+\phi\left(k_{f}-k_{p}\right)}\right]
\end{gathered}
$$

The following are the dimensionless terms are used to obtain dimensionless governing equations are: 


$$
\begin{gathered}
X=x / L, Y=y / L, U=\frac{u L}{\alpha_{f}}, V=\frac{v L}{\alpha_{f}}, P=\frac{p L^{2}}{\rho_{n f \alpha_{f}^{2}}}, \theta= \\
\frac{\left(T-T_{c}\right)}{\left(T_{h}-T_{c}\right)} .
\end{gathered}
$$

The dimensionless fluid flow and energy equations are expressed as follows:

$$
\begin{gathered}
\frac{\partial U}{\partial X}+\frac{\partial V}{\partial Y}=0 \\
U \frac{\partial U}{\partial X}+V \frac{\partial U}{\partial Y}=-\frac{\partial P}{\partial X}+\frac{\mu_{n f}}{\rho_{n f} \alpha_{f}}\left(\frac{\partial^{2} U}{\partial X^{2}}+\frac{\partial^{2} U}{\partial Y^{2}}\right) \\
U \frac{\partial V}{\partial X}+V \frac{\partial V}{\partial Y}=-\frac{\partial P}{\partial Y}+\frac{\mu_{n f}}{\rho_{n f} \alpha_{f}}\left(\frac{\partial^{2} V}{\partial X^{2}}+\frac{\partial^{2} V}{\partial Y^{2}}\right)+\frac{(\rho \beta)_{n f}}{\rho_{n f} \beta_{n f}} R a N \operatorname{Pr} \theta \\
U \frac{\partial \theta}{\partial X}+V \frac{\partial \theta}{\partial Y}=\frac{\alpha_{n f}}{\alpha_{f}}\left[\left(\frac{\partial^{2} \theta}{\partial X^{2}}+\frac{\partial^{2} \theta}{\partial Y^{2}}\right)\right] \\
R a N=\frac{g \beta_{f} L^{3}\left(T_{h}-T_{c}\right)}{v_{f} \alpha_{f}} \\
\operatorname{Pr}=\frac{v_{f}}{\alpha_{f}}
\end{gathered}
$$

The local and $\mathrm{Nu}_{\text {avg }}$ on the bottom surface is calculated by using the following expressions:

$$
N u_{l}=-\left.\frac{k_{n f}}{k_{f}} \frac{\partial \theta}{\partial Y}\right|_{Y=0}
$$

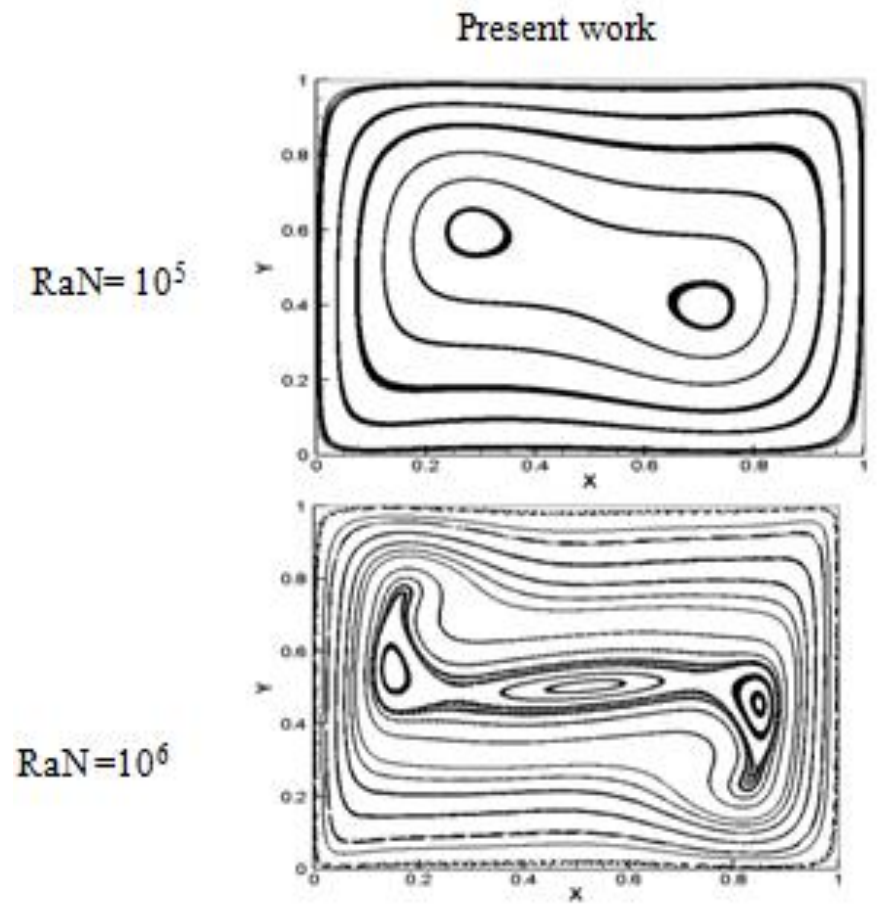

$$
N u_{\text {avg }}=\frac{1}{A} \int_{0}^{1} N u_{l} d A
$$

\subsection{Boundary conditions}

The non-dimensional boundary conditions along the walls of the square cavity are applied as:

At left surface $(X=0$ and $0 \leq Y \leq 1) U=V=\theta=0$.

At right surface $(X=1$ and $0 \leq Y \leq 1) U=V=\theta=0$.

At top surface $(\mathrm{Y}=1$ and $0 \leq \mathrm{X} \leq 1) \mathrm{U}=\mathrm{V}=\frac{\partial \theta}{\partial Y}=0$.

At bottom surface $(Y=0$ and $0 \leq X \leq 1) U=V=\theta=0$, whereas along the two heat sources, $\theta=1$.

\section{NUMERICAL SCHEME AND VALIDATION}

The non-dimensional fluid flow and energy equations are discretized using finite volume method. Table 1 shows the properties of the water and $\mathrm{Cu}$ nanoparticles used for the study. The SIMPLE algorithm was applied to link the continuity and momentum equations. The convective and diffusive terms in the momentum and energy equations are handled withQuadratic Upstream Interpolation for Convective Kinematics (QUICK) scheme. The discretized linear equations are solved by Tri-Diagonal Matrix Algorithm (TDMA) method. The developed numerical code was validated in terms of $\mathrm{Nu}_{\text {avg }}$, streamlines and isothermal contours by varying RaN for natural convection heat transfer. It was done considering the cavity with air as a medium inside the square cavity. The left wall was maintained hot and right wall was cooled while the top and bottom walls were considered as adiabatic. The obtained results are in good agreement with the work reported by the De Vahl Davis [11] as shown in Figures 2 and 3. A comparison of results of this numerical study with that of literature has been presented in Table 2. 

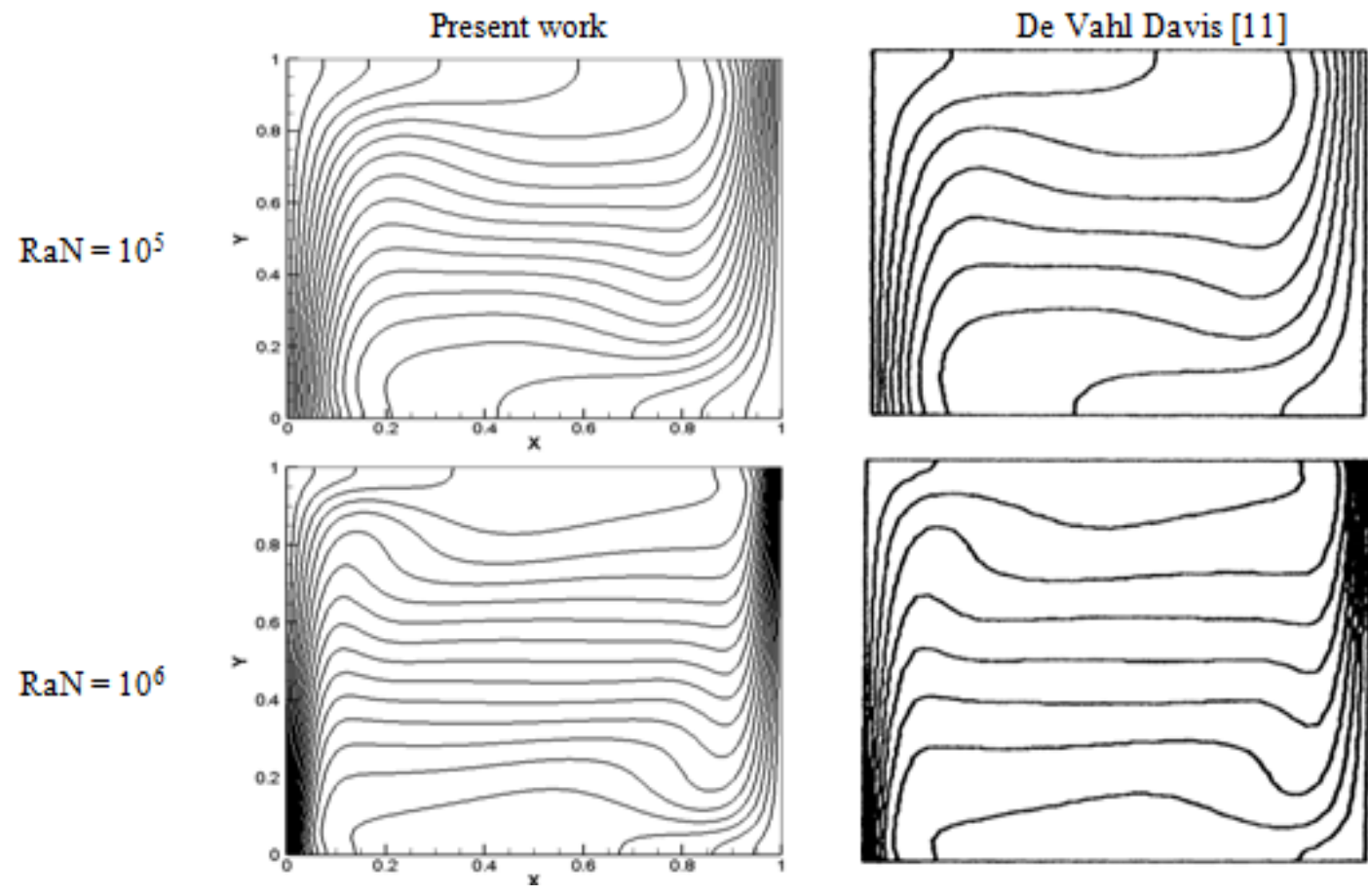

Figure 3. Comparison of constant temperature lines with benchmark results of De VahlDavis[11] $\left(\operatorname{RaN}=10^{5}\right.$ and $\left.10^{6}, \operatorname{Pr}=0.71\right)$

Table 1. Thermo physical properties of water and $\mathrm{Cu}$ nanoparticles [8]

\begin{tabular}{ccccc}
\hline & $\boldsymbol{\rho}\left(\mathbf{k g} / \mathbf{m}^{\mathbf{3}}\right)$ & $\mathbf{C}_{\mathbf{p}}(\mathbf{J} / \mathbf{k g ~ K})$ & $\mathbf{k}(\mathbf{W} / \mathbf{~ m ~ K})$ & $\boldsymbol{\beta}(\mathbf{1} / \mathbf{K})$ \\
\hline Water & 997.1 & 4179 & 0.63 & $1.47 \times 10^{-5}$ \\
$\mathrm{Cu}$ & 8933 & 385 & 401 & $1.67 \times 10^{-5}$ \\
\hline
\end{tabular}

\subsection{Grid independence study}

The grid independence test is carried outto determine optimum grid size for the present developed numerical code for the case of $10 \%$ volume fraction of $\mathrm{Cu}$-nanoparticles $(\Phi=10 \%)$ in the base fluid. Different uniform grids namely, 20 x 20, $40 \times 40,60 \times 60,80 \times 80,100 \times 100$ and $120 \times 120$ were tested. It was observed, as mentioned in Table 3, that the $\mathrm{Nu}_{\text {avg }}$ remained nearly same from grids $80 \times 80$ to $120 \times 120$ at $\mathrm{RaN}$ of $10^{4}$. Hence $80 \times 80$ gridis selected for further study.

Table 2. Validation of $\mathrm{Nu}_{\mathrm{avg}}$ along the left heated wall with De Vahl Davis [11]

\begin{tabular}{ccc}
\hline & Present Work & De Vahl Davis \\
\hline $\mathrm{RaN}=10^{3}$ & 1.134 & 1.11 \\
$\mathrm{RaN}=10^{4}$ & 2.102 & 2.243 \\
$\mathrm{RaN}=10^{5}$ & 4.53 & 4.519 \\
$\mathrm{RaN}=10^{6}$ & 8.99 & 8.799 \\
\hline
\end{tabular}

Table 3. Grid Independence test $\left(\Phi=10 \%, \mathrm{Ra}=10^{4}, \mathrm{Pr}=6.2\right)$

\begin{tabular}{ccccccc}
\hline Grid size & $20 \times 20$ & $40 \times 40$ & $60 \times 60$ & $80 \times 80$ & $100 \times 100$ & $120 \times 120$ \\
\hline $\mathrm{Nu}_{\text {avg }}$ & 1.617 & 1.789 & 1.857 & 1.89 & 1.895 & 1.899 \\
\hline
\end{tabular}

\section{RESULTS AND DISCUSSION}

A steady, two dimensional numerical investigations is carried out to study the buoyancy driven flows of $\mathrm{Cu}$-Water $\mathrm{NF}$ in a cavity with two constant temperature heat sources placed on its bottom surface. The results presented here mainly focus on influence of $\mathrm{RaN}$ and volume fraction of nanoparticles on streamlines, fluid velocities and convective heat transfer characteristics of the NFs in the cavity. The value of $\mathrm{RaN}$ is varied from 1000 to $10^{6}$ and the volume fraction of $\mathrm{Cu}$-nano sized particles is varied from 0 to $20 \%(\varphi=0 \%, 5 \%$, $10 \%, 15 \%$ and $20 \%$ ). Prandtl number of the fluid, Pris taken as 6.2 for the entirestudy [7].

\subsection{Influence of RaN on flow characteristics}

Figures 4 and 5 show the development of streamlines and corresponding velocity vectors in the cavity. The cavity is filled with copper nanofluid in which volume fraction of $\mathrm{Cu}$ particles is $10 \%$ and the $\mathrm{RaN}$ is varied from $10^{3}$ to $10^{6}$. It is observed, since the two constant temperature heat sources of same strength are located at equal distance from the sides in the bottom surface, a set of primary counter rotating streamlines are developed rising from the surfaces of heat sources, reaching top, and again moving down from the sides of cavity. It can also be observed from the Figure 4(a) that secondary small counter rotating vortices are formed in the region between the two heat sources. These vortices are found to be rotating in a direction opposite to that of the main streamlines which are moving upwards. The size of these two vortices is also noticed to be decreasing with the increase in $\mathrm{RaN}$ due to dominant effect of primary vortices. At the same time, it can be observedin Figures 4(a) to 4(d) that two counter rotating vortices, above the heat sources, move towards up with increase in RaN. This may be due to increase in the buoyancy forces experienced by NFs. 


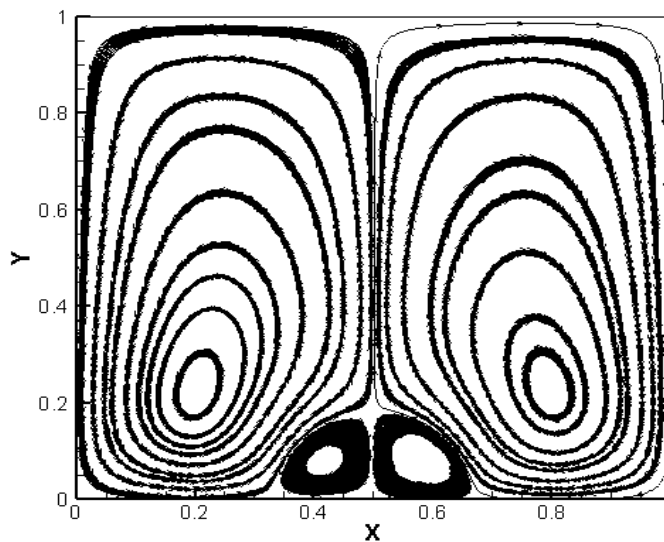

(a) $\mathrm{RaN}=10^{3}$

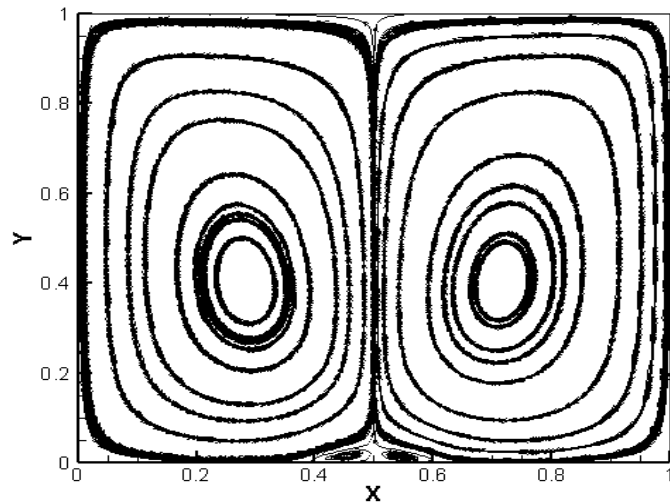

(c) $\mathrm{RaN}=10^{5}$

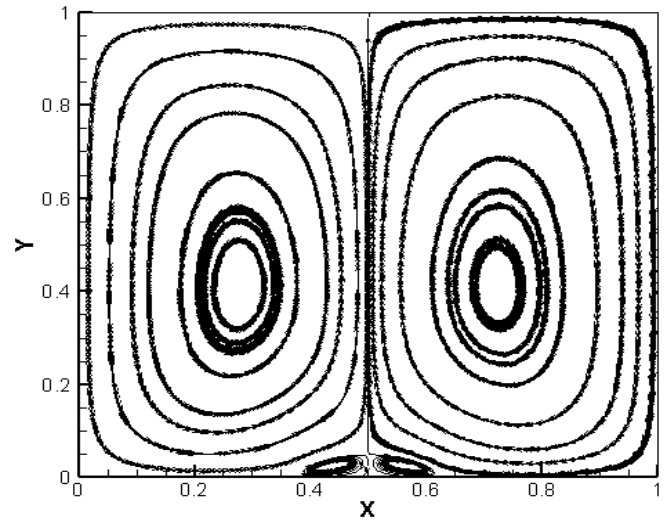

(b) $\mathrm{RaN}=10^{4}$

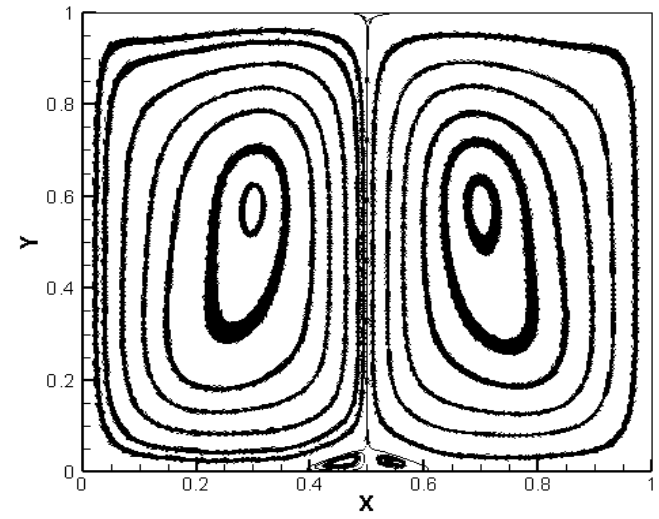

(d) $\mathrm{RaN}=10^{6}$

Figure 4. Stream lines for different RaNfor $\Phi=10$ percent volume fraction of nanoparticles

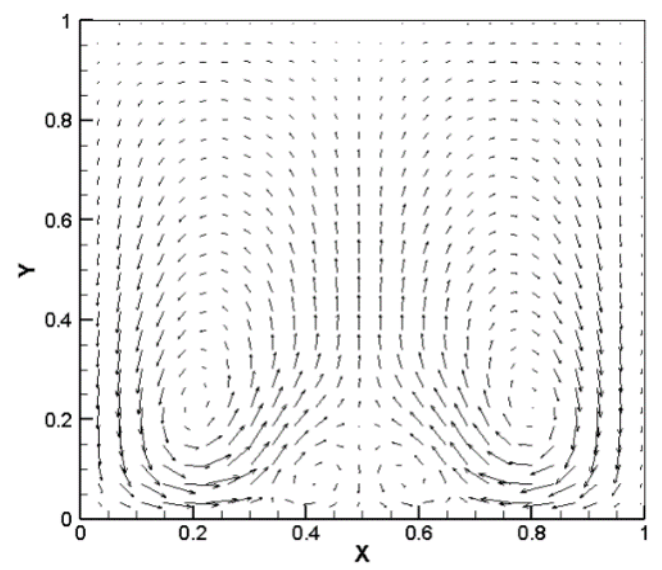

(a) $\mathrm{Ra}=10^{3}$

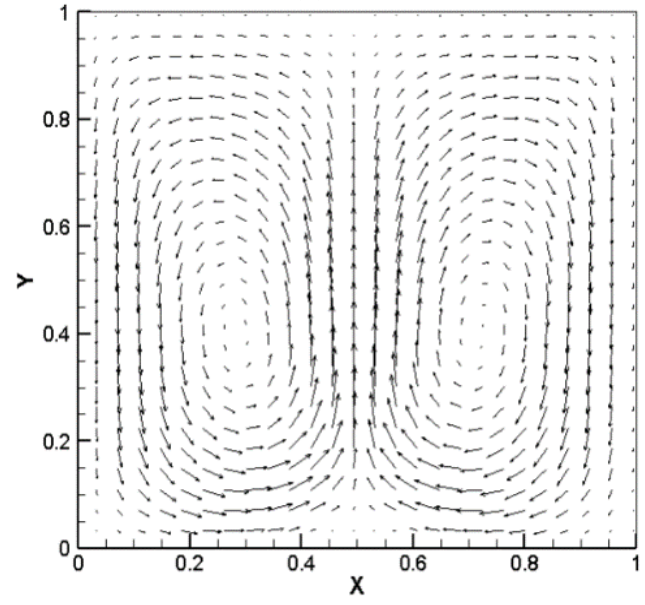

(c) $\mathrm{Ra}=10^{5}$

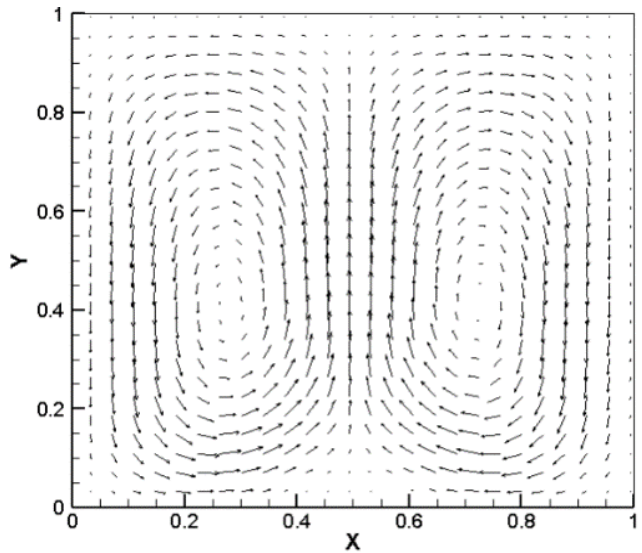

(b) $\mathrm{Ra}=10^{4}$

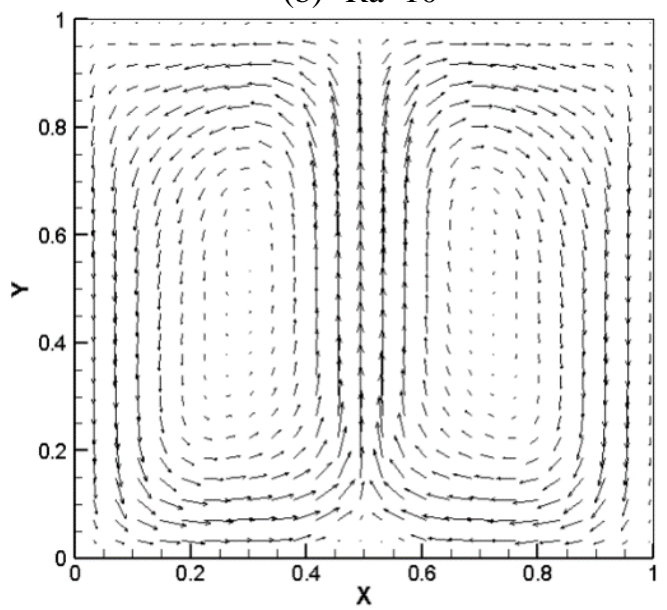

(d) $\mathrm{Ra}=10^{6}$

Figure 5. Velocity vectors for different $\mathrm{RaN}$ for $\Phi=10$ percent volume fraction of nanoparticles 


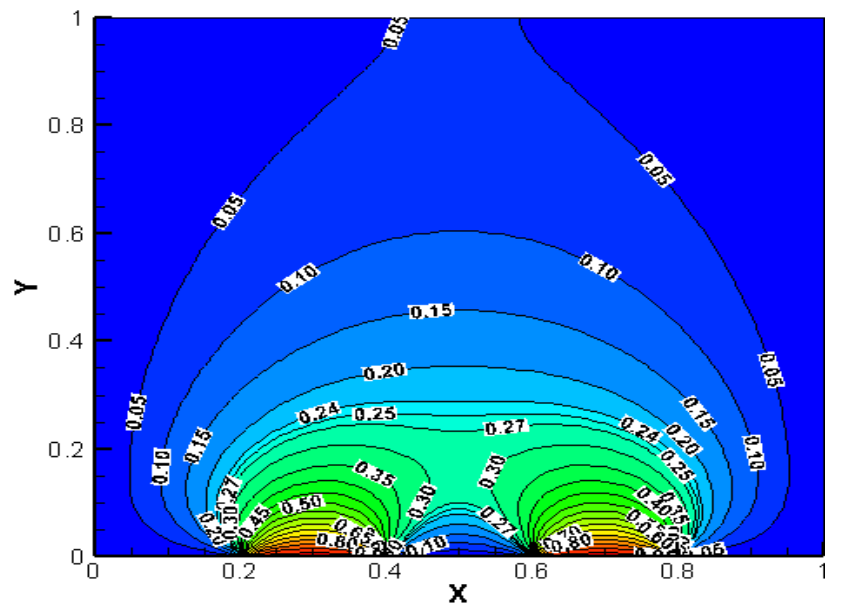

(a) $\mathrm{RaN}=10^{3}$

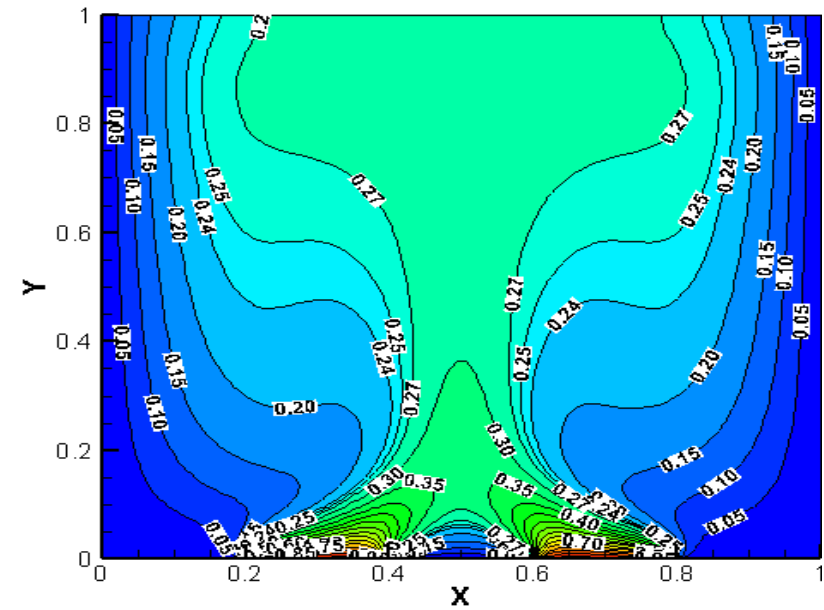

(c) $\mathrm{RaN}=10^{5}$

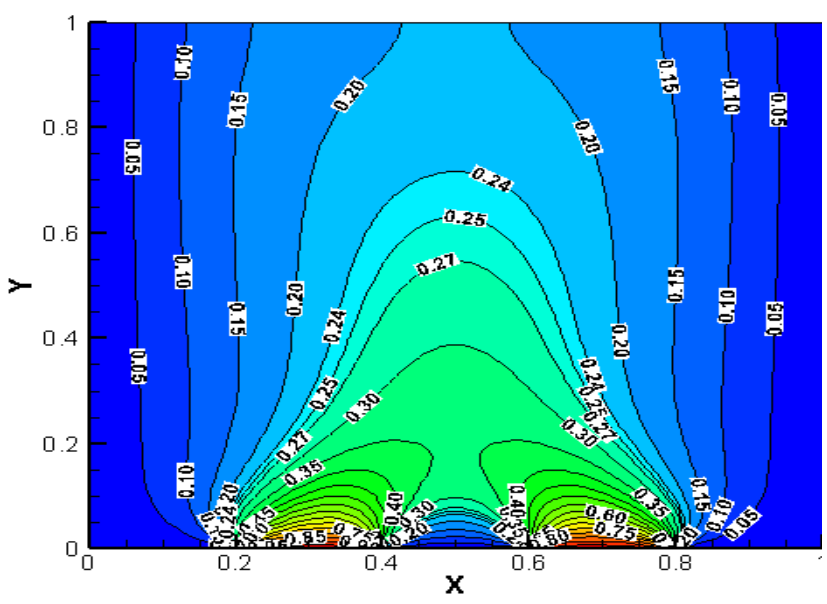

(b) $\mathrm{RaN}=10^{4}$

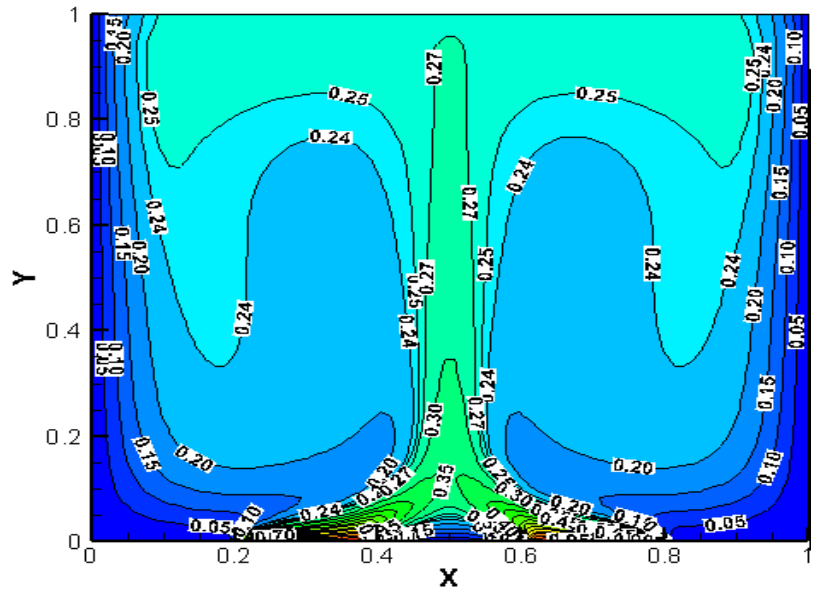

(d) $\mathrm{RaN}=10^{6}$

Figure 6. Constant temperature lines for different $\operatorname{RaNfor} \Phi=10$ percent volume fraction of nanoparticles

\subsection{Influence of RaN on constant temperature lines}

Figure 6(a) to 6(d) shows the formation of constant temperature lines on the heated sources inside the cavity for different RaN. As it can be seen in the figures, constant temperature lines are formed nearly parallel to each other close to the two hot sources for low RaN of $10^{3}$ and $10^{4}$ due to the influence of conduction heat transfer on the fluid flow with low heat transfer to the NF. However, higher convective heat transfer rate is observed at increased $\mathrm{RaN}$, especially at $10^{6}$. This can be attributed to the increase in buoyancy forces because of which natural convection dominates than the conduction heat transfer at the hot surfaces. Similar observations were reported in the literature [7] for single heated source.

\subsection{Influence of volume fraction of nanoparticles on vertical component of velocity, $\mathrm{V}$}

The influence of volumetric percentage addition of nanoparticles on vertical velocity component, $\mathrm{V}$, of the nanofluid along the mid horizontal line of the square cavity for different RaN is presented in Figure 7. It is observed from Figure 7(a) that the vertical velocity component decreases with increase in volume fraction of nanoparticles at low RaN, especially at $10^{3}$. But with the increase in RaN from $10^{4}$ to $10^{6}$, the vertical velocity component is found to be increasing at 5 percent volume fraction of nanoparticles compared to pure base fluid. However, it starts to decrease with further addition of nanoparticles and this decrease is found to be consistent up to $20 \%$ as shown in Figures 7 (b) to $7(\mathrm{~d})$. The decrease in vertical velocity component might be due to heavier density and rise in viscosity of NF with the addition of nanoparticles. But the value of vertical velocity component increases by increasing RaN from $10^{3}$ to $10^{6}$ and this variation is due to higher buoyancy driven forces inside the cavity. The higher value of velocity is recorded at mid vertical line of the cavity due to equal distance of heat sources from side surfaces. At the two vertical surfaces, velocity becomes zero due to wall effect, and in the region between the vertical walls and heat sources, negative vertical velocity is recorded due to downward motion of the fluid particles.

\subsection{Influence of volume fraction of nanoparticles and RaN on local Nusselt number}

The influence of volume fraction of nanoparticles and RaN on local Nusselt number $\left(\mathrm{Nu}_{\mathrm{L}}\right)$ along the bottom surface of the cavity with two heat sources is shown from Figures 8(a) to 8(d). For a given percentage addition of nanoparticles, the local Nusselt number varies over the heated sources, having maximum at its ends and negative in the region between two heat sources due to heat flow from fluid to surface. For $\mathrm{RaN}=10^{3}$ and $10^{4}$, local Nusselt number has symmetrically distributed over the heated surfaces due to the dominanceof heat conduction. With the increase in $\mathrm{RaN}$ from $10^{5}$ to $10^{6}$, an increase in values of local Nusselt number is observed due to increase in buoyancy forces over the heated surfaces. The 
change of local Nusselt number over the two heated surfaces for $\mathrm{RaN}=10^{3}$ and $10^{4}$ is symmetrical, whereas for $\mathrm{RaN}=10^{5}$ and $10^{6}$ it is un symmetrical. Local Nusselt number is also strongly dependent on volume fraction of nanoparticles in the

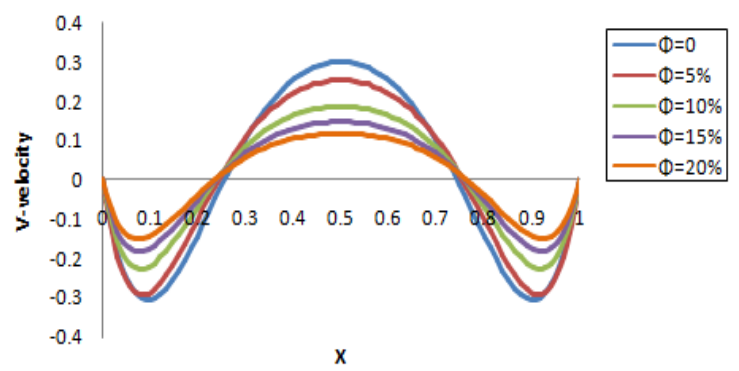

(a) $\mathrm{RaN}=10^{3}$

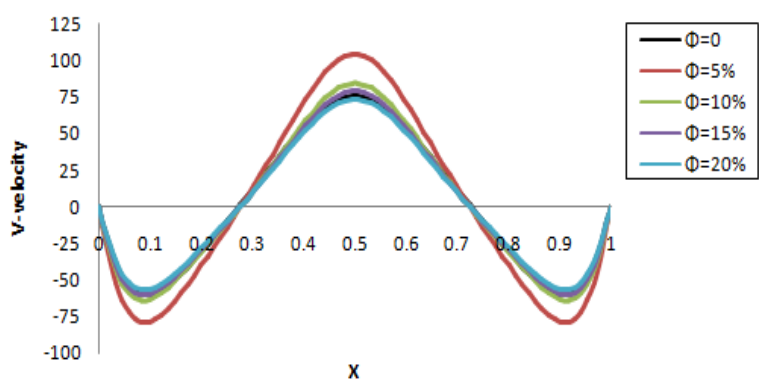

(c) $\mathrm{RaN}=10^{5}$ base fluid as can be observed from Figure 8 (a) to 8 (d). The addition of volume fraction of nanoparticles causes irregular and random motion of nanoparticles resulting enhancement in energy transfer rates [8].

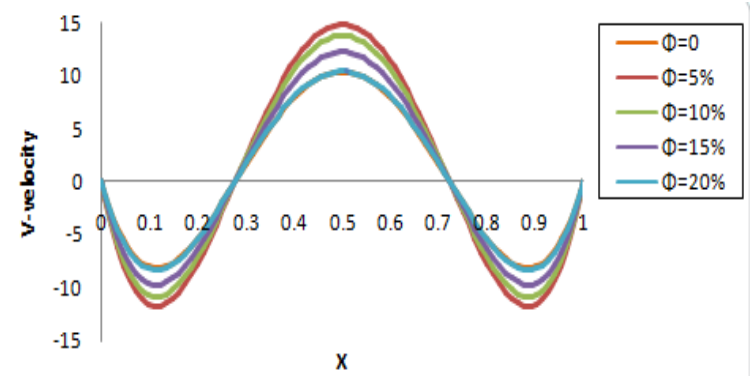

(b) $\mathrm{RaN}=10^{4}$

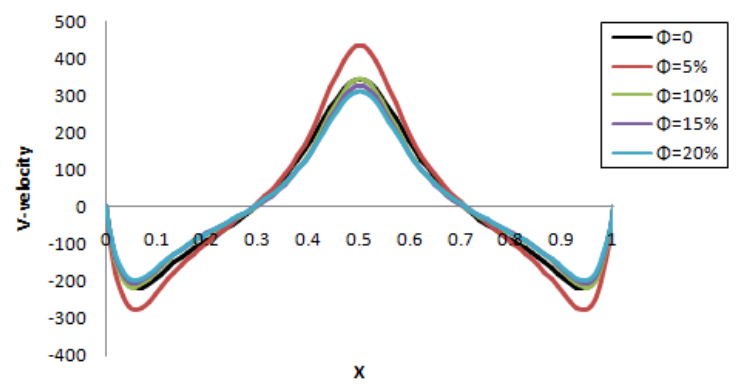

(d) $\mathrm{RaN}=10^{6}$

Figure 7. Change of vertical component of velocity, $\mathrm{V}$, along the mid horizontal line of square cavity by varying RaN from $10^{3}$ to $10^{6}$ for different volume percentage addition of $\mathrm{Cu}$-nanoparticles

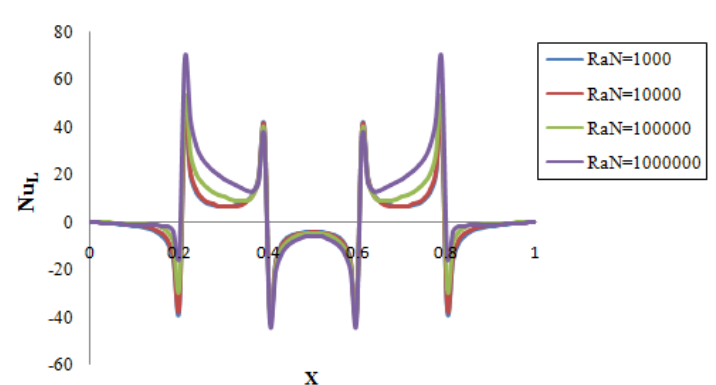

(a) $\Phi=0 \%$

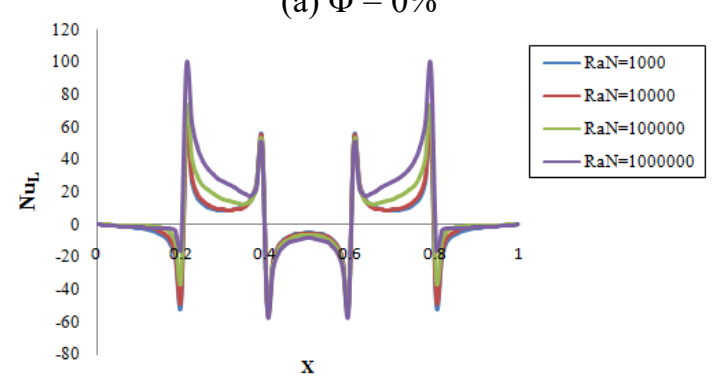

(c) $\Phi=10 \%$

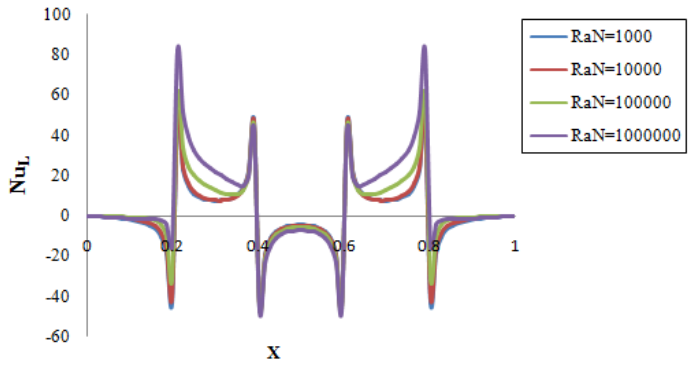

(b) $\Phi=5 \%$

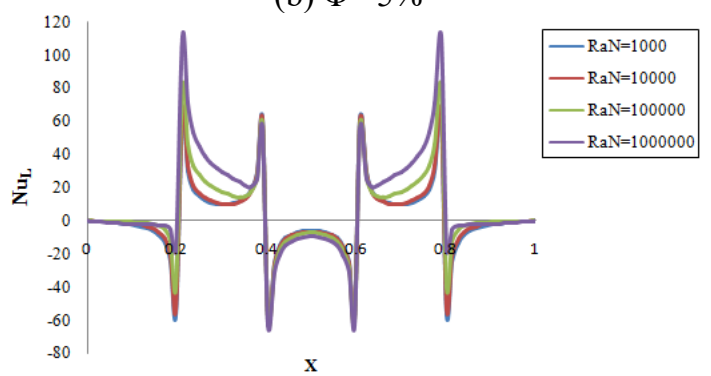

(d) $\Phi=15 \%$

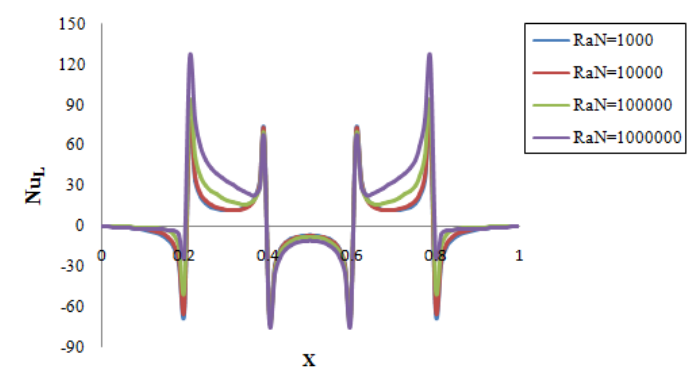

(e) $\Phi=20 \%$

Figure 8. Change of Local Nusselt number along the bottom surface of square cavity for different volume fractions of $\mathrm{Cu}$ nanoparticles and RaN 


\subsection{Influence of volume fraction of $\mathrm{Cu}$-nanoparticles in a base fluid and $\mathrm{RaN}$ on $\mathrm{Nu}$ avg along the bottom surface}

Figure 9 illustrates the change inNu $\mathrm{uvg}_{\text {avg }}$ along the bottom surface of square cavity filled with $\mathrm{NF}$ of $\mathrm{Cu}$-Water at different volume fractions of nano particles (from 5\% to 20\%) for different RaNs ranging from $10^{3}$ to $10^{6}$. The addition of nanoparticles to the base fluid causes thermal conductivity of NF to be higher than base fluid and this will be proportional to the volume percentage addition of nanoparticles [1]. For low $\operatorname{RaN}\left(\mathrm{RaN}=10^{3}\right.$ and $\left.10^{4}\right)$, there is a slight increase in $\mathrm{Nu}_{\text {avg }}$ due to the dominant effect of conduction mode of heat transfer over the convection atthe bottom surface. The convective heat transfer is found to be dominant over the conduction heat transfer with the increase in $\mathrm{RaN}\left(\right.$ from $\mathrm{RaN}=10^{5}$ and $10^{6}$ ) and volume fraction of nano particles in the base fluid. This is due to the increase in buoyancy forces inside the cavity which resulted in significant increase in heat transfer along the bottom surface.

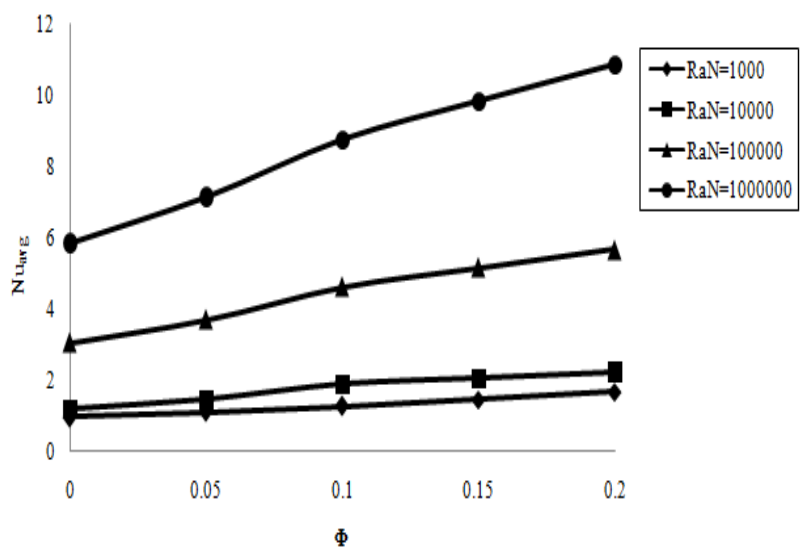

Figure 9. Comparison of $\mathrm{Nu}_{\text {avg }}$ along the bottom surface with increase in volume fraction of $\mathrm{Cu}$-particles for $\mathrm{RaN}$ varying from $10^{3}$ to $10^{6}$

\section{CONCLUSIONS}

This work numerically investigates the effect of $\mathrm{RaN}$ and volume fractions of nano particles in a cavity filled with Copper-Water NF using finite volume method and SIMPLE algorithm. The important conclusions from the study are presented below:

(1) It causes significant changes in fluid flow streamlines and isothermal lines with the increase in RaN from $10^{3}$ to $10^{6}$.

(2) For low RaN, conduction heat transfer near the bottom surface is found to be dominating over the convection.

(3) There is a significant increase in fluid velocities with increase in RaN causing counter rotating streamlines to move away from heat sources, increasing the heat transfer rate.

(4) $\mathrm{Nu}_{\text {avg }}$ along the bottom surface is found to be increasing with the increase in $\mathrm{RaN}$ and volume fraction of nano particles in the base fluid.

(5) A reduction in fluid velocities at horizontal mid sections of the cavity is observed at higher volume fractions of nano particles in the base fluid.

(6) The variation of local Nusselt number is noticed to be symmetrical over the heated sources for low $\operatorname{RaN}\left(10^{3}\right.$ and $\left.10^{4}\right)$ due to domination of heat conduction and it is unsymmetrical for high $\mathrm{RaN}\left(10^{5}\right.$ and $\left.10^{6}\right)$ due to high fluid velocities and convective heat transfer.

\section{REFERENCES}

[1] Choi, S.U., Eastman, J.A. (1995). Enhancing thermal conductivity of fluids with nanoparticles (No. ANL/MSD/CP-84938; CONF-951135-29). Argonne National Lab., IL, United States.

[2] Xuan, Y., Li, Q. (2000). Heat transfer enhancement of nanofluids. International Journal of Heat and Fluid Flow, 21(1): $\quad 58-64 . \quad \mathrm{http}: / / \mathrm{dx}$. doi.org/10.1016/S0142727X(99)00067-3

[3] Tzou, D.Y. (2008). Thermal instability of nanofluids in natural convection. International Journal of Heat and Mass Transfer, 51(11-12): 2967-2979. http://dx.doi.org/10.1016/j.ijheatmasstransfer.2007.09.0 14

[4] Khanafer, K., Vafai, K., Lightstone, M. (2003). Buoyancy-driven heat transfer enhancement in a twodimensional enclosure utilizing nanofluids. International Journal of Heat and Mass Transfer, 46(19): 3639-3653. http://dx.doi.org/10.1016/S0017-9310(03)00156-X

[5] Putra, N., Roetzel, W., Das, S.K. (2003). Natural convection of nano-fluids. Heat and Mass Transfer, 39(89): 775-784. http://dx.doi.org/10.1007/s00231-0020382-z

[6] Sheikhzadeh, G.A., Arefmanesh, A., Mahmoodi, M. (2011). Numerical study of natural convection in a differentially-heated rectangular cavity filled with $\mathrm{TiO}_{2}$ water nanofluid. In Journal of Nano Research, 13: 75-80. https://doi.org/10.4028/www.scientific.net/JNanoR.13.7 5.

[7] Aminossadati, S.M., Ghasemi, B. (2009). Natural convection cooling of a localised heat source at the bottom of a nanofluid-filled enclosure. European Journal of Mechanics-B/Fluids, 28(5): 630-640. http://dx.doi.org/10.1016/j.euromechflu.2009.05.006

[8] El Bouihi, I., Sehaqui, R. (2012). Numerical study of natural convection in a two-dimensional enclosure with a sinusoidal boundary thermal condition utilizing nanofluid. Engineering, 4(8): 445-452. http://dx.doi.org/10.4236/eng.2012.48058

[9] Xiong, X., Chen, S., Yang, B. (2017). Natural convection of $\mathrm{SiO}_{2}$-water nanofluid in square cavity with thermal square column. Applied Mathematics and Mechanics, 38(4): 585-602. http://dx.doi.org/10.1007/s10483-0172183-6

[10] Roy, N.C. (2018). Natural convection of nanofluids in a square enclosure with different shapes of inner geometry. Physics of Fluids, 30(11): 113605. http://dx.doi.org/10.1063/1.5055663

[11] de Vahl Davis, G. (1983). Natural convection of air in a square cavity: A bench mark numerical solution. International Journal for Numerical Methods in Fluids, 3(3): 249-264. http://dx.doi.org/10.1002/fld.1650030305

[12] Patankar, S.V. (1980). Numerical Heat Transfer and Fluid Flow. Washington, DC, Hemisphere Publishing Corp., 210p. http://dx.doi.org/10.1201/9781482234213

[13] Brinkman, H.C. (1952). The viscosity of concentrated suspensions and solutions. The Journal of Chemical Physics, 20(4): 571-571. http://dx.doi.org/10.1063/1.1700493

[14] Maxwell, J.C. (1881). A Treatise on Electricity and Magnetism (Vol. 1). Clarendon Press. http://dx.doi.org/10.1017/CBO9780511709340 
[15] Bhattad, A., Sarkar, J., Ghosh, P. (2018). Improving the performance of refrigeration systems by using nanofluids: a comprehensive review. Renewable and Sustainable Energy Reviews, 82: 3656-3669. http://dx.doi.org/10.1016/j.rser.2017.10.097

[16] Bhattad, A., Sarkar, J., Ghosh, P. (2018). Discrete phase numerical model and experimental study of hybrid nanofluid heat transfer and pressure drop in plate heat exchanger. International Communications in Heat and Mass Transfer, 91: 262-273. http://dx.doi.org/10.1016/j.icheatmasstransfer.2017.12.0 20

\section{NOMENCLATURE}

$\mathrm{C}_{\mathrm{p}} \quad$ specific heat, $(\mathrm{J} / \mathrm{Kg} \mathrm{K})$

$\mathrm{g}$ acceleration due to gravity, $\left(\mathrm{m} / \mathrm{s}^{2}\right)$

$\mathrm{k}$ thermal conductivity, (W/m K)

NFS nanofluids

$\mathrm{Nu}_{\mathrm{L}} \quad$ Local Nusselt number

$\mathrm{Nu}_{\text {avg }} \quad$ Average Nusselt number

$\mathrm{Pr} \quad$ Prandtl number

$\mathrm{p} \quad$ Fluid pressure, $(\mathrm{Pa})$

$\mathrm{P} \quad$ Non dimensional pressure

RaN Rayleigh number
$\mathrm{T}$ dimensional temperature, $(\mathrm{K})$

$\mathrm{u}, \mathrm{v}$ dimensional $\mathrm{x}$ and $\mathrm{y}$ components of velocity, $\left(\mathrm{ms}^{-1}\right)$

$\mathrm{U}, \mathrm{V}$ dimensionless velocities

$\mathrm{x}, \mathrm{y} \quad$ dimensional coordinates, $(\mathrm{m})$

$\mathrm{X}, \mathrm{Y}$ dimensionless coordinates

L Length of the cavity, (m)

$\mathrm{Cu} \quad$ Copper nanoparticles

\section{Greek symbols}

$\alpha \quad$ thermal diffusivity, $\left(\mathrm{m}^{2} \mathrm{~s}^{-1}\right)$

$\beta \quad$ thermal expansion coefficient, $\left(\mathrm{K}^{-1}\right)$

$\Phi$ nanoparticles volume fraction

$\theta \quad$ non dimensional temperature

$\mu \quad$ Dynamic viscosity, $\left(\mathrm{N} \mathrm{s} \mathrm{m}^{-2}\right)$

$v \quad$ kinematic viscosity, $\left(\mathrm{m}^{2} \mathrm{~s}^{-1}\right)$

$\rho \quad$ Density, $\left(\mathrm{kg} \mathrm{m}^{-3}\right)$

\section{Subscripts}

c cold surface

f fluid

h hot surface

nf nanofluid

s Solid particles 